\title{
Study on heat transfer performance of geothermal pile- foundation heat exchanger in GSHP system
}

\author{
Hezhi Zhang, Bo Xu, Zhenqian Chen * \\ School of Energy and Environment, Southeast University, Nanjing 210096, China
}

\begin{abstract}
In order to study the heat transfer performance of geothermal pile-foundation heat exchanger in ground source heat pump system (GSHP), the physical models of pile-foundation heat exchanger and heat exchanger group were established. The heat transfer processes of pile-foundation heat exchanger and heat transfer performance was analyzed both in cooling and heating mode. To carry out the simulation of heat transfer process for $3 \times 3$ energy piles, an office building located in Nanjing was introduced. The all-year dynamic building load was calculated with DeST, including the cooling period from June to September, the heating period from December to March and two recovery periods. After ten year's running, the average soil temperature increases in non-equilibrium condition. Study results are approximate to the actual situation and can be used as theoretical basis for the design and application of pilefoundation heat exchanger in GSHP system.
\end{abstract}

\section{INTRODUCTION}

Nowadays, urban heating has been accounting for the largest proportion of the total building energy consumption in China [1]. By extracting heat into and injecting heat from soil, GSHP system can run stably by avoiding the impact of weather changes on system performance, meeting the requirements of sustainable development strategy. Without material exchanges with atmosphere, the pollution of waste heat, vapor and noise can be reduced. Moreover, GSHP system has a great advantage in investment and maintenance costs [2].

However, the disadvantages of GSHP system cannot be ignored neither. To invest a new system, a large area of land is needed and drilling holes costs additional investment. Heat transfer performance of heat exchangers with different configurations including single U-shaped, single W-shaped, double U-shaped, treble U-shaped and spiral forms were studied and analyzed [3][4]. The structures of double U-shaped and treble U-shaped are more complex, and the latter one has the higher heat transfer efficiency obviously [5]. In practical engineering applications, stability and rigidity in pile-foundation heat exchangers were verified to be crucial to the efficient operation of system [6].

\footnotetext{
${ }^{*}$ Corresponding author: zqchen $@$,seu.edu.cn
}

In this paper, the treble U-shaped form of geothermal pile-foundation heat exchangers in GSHP system was selected and studied by simulation. The simulation processes were carried out by Fluent based on the Finite Element Method for Nanjing area. Heat transfer processes of pile-foundation heat exchanger and heat exchanger group were studied in different conditions.

\section{MODELS AND METHODS}

\subsection{Physical models}

The physical models and configurations of pilefoundation heat exchanger and heat exchanger group, shown in Fig. 1. The physical model of pile-foundation heat exchanger was a vertical cylinder with the diameter of $d_{1}$ and depth of $h_{1}$. The concrete pile with treble Ushaped pipes was laid inside soil with diameter of $d_{2}$ and depth of $h_{2}$. Piles were HDPE with inner diameter of $d_{3}$, thickness and depth of $h_{3} .3 \times 3$ piles were chosen to constitute the model of heat exchanger group. The relevant model parameters were listed in Table 2.

Table 2. Model parameters 


\begin{tabular}{cccccccccc}
\hline Par & & & & & & & \\
am & $\mathrm{h}_{1} /$ & $\mathrm{H}_{2} /$ & $\mathrm{H}_{3} /$ & $\mathrm{d}_{1} /$ & $\mathrm{d}_{2} /$ & $\mathrm{d}_{3} /$ & $\mathrm{l}_{1} /$ & $\mathrm{l}_{2} /$ & $\mathrm{k} /$ \\
eter & $\mathrm{m}$ & $\mathrm{m}$ & $\mathrm{m}$ & $\mathrm{m}$ & $\mathrm{m}$ & $\mathrm{m}$ & $\mathrm{m}$ & $\mathrm{m}$ & $\mathrm{m}$ \\
\hline Val & & & & & & 0.0 & & & 0.0 \\
ue & 30 & 28 & 27 & 20 & 0.6 & 2 & 0.2 & 0.1 & 03 \\
\hline
\end{tabular}

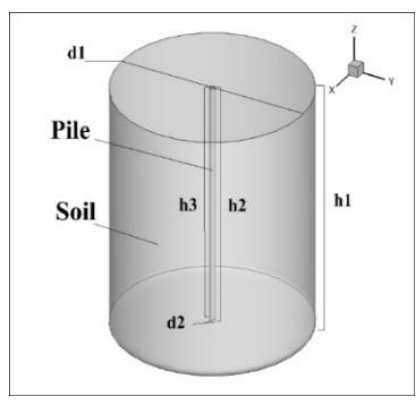

a. Pile-foundation heat exchanger

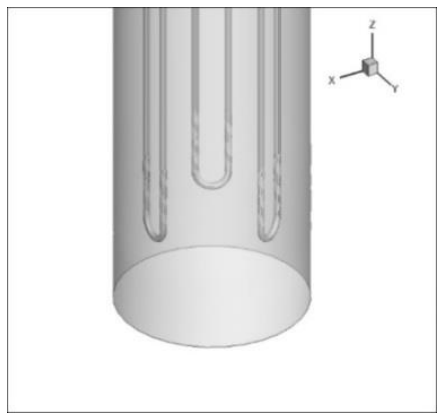

b. Bottom of heat exchanger

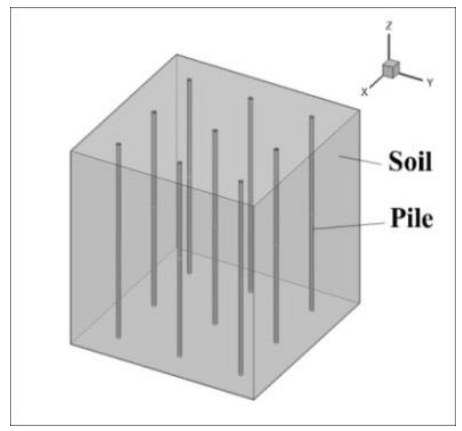

c. Pile-foundation heat exchanger group

Fig. 1. Physical models and specifications

\subsection{Solution and method}

When simulation for heat transfer performance of pile-foundation heat exchanger was carried out, inlet velocity of water was set to be $0.6 \mathrm{~m} \cdot \mathrm{s}^{-1}$ and inlet temperature was specified about $308 \mathrm{~K}$. The Reynold number of flow in pipes was more than 7000 , indicating the turbulent water flow. Consequently, standard k- $\varepsilon$ was opted for simulation as well as energy equation. Turbulence intensity was calculated about $5 \%$ based on $0.16 \times \mathrm{Re}^{-1 / 8}$ equation. For Nanjing area, the initial temperature of soil and piles was set to be $291 \mathrm{~K}$ and the temperature of outer surfaces was treated as constant according to the Dirichlet Problem [8]. SIMPLE algorithm was selected to evaluate the pressure-velocity coupling in the flowing section. Relevant initial and boundary conditions were considered. For pile-foundation heat exchanger group, four User Defined Function (UDF) programs were programmed as source items according to calculating data of dynamic building load.

\section{RESULTS AND DISCUSSION}

\subsection{Pile-foundation heat exchanger}

In order to observe and analyze simulation results, plane $\mathrm{M}(\mathrm{X}=0.2 \mathrm{~m})$ and line $\mathrm{L}(\mathrm{Y}=0.0 \mathrm{~m}, \mathrm{Z}=-15.0 \mathrm{~m})$ in the model were created. In cooling and heating modes, heat transfer simulations with system running for one month were carried out, shown in Fig. 2. With the operation of system, the heat effect radius of heat exchanger on the soil kept expanding, while its increasing rate gradually decreased. With pile foundation as the center, the temperature of surrounding soil increased gradually in cooling mode and decreased gradually in heating mode. In the $x-y$ plane, the soil temperature rose more quickly in cooling mode and decreased more rapidly in heating mode with closer to the pile foundation wall surface, by the effect of temperature gradient in the radial direction within the range of thermal action.

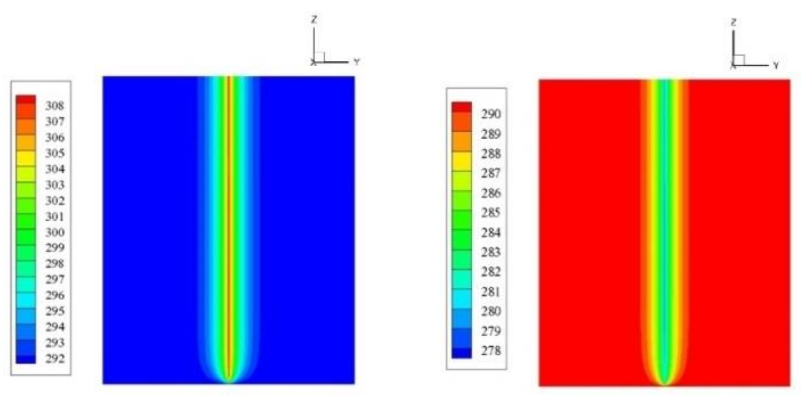

a. On plane M after one month 

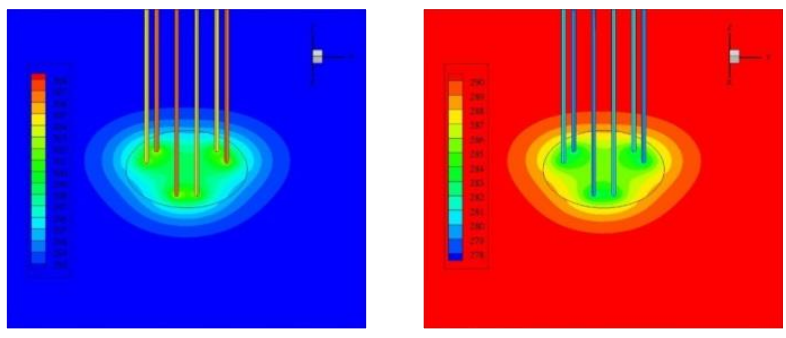

b. Inside the pile after one hour

Fig. 2. Temperature distributions in cooling and heating mode

The temperature distributions on line $\mathrm{L}$ inside the concrete pile with system running are depicted in the following Fig. 3. The position of concrete pile is between $-0.3 \mathrm{~m}$ and $0.3 \mathrm{~m}$. It can be concluded that, in cooling mode, the temperature in concrete pile was obviously higher than that in soil. Moreover, soil temperature decreased with the increasing of distance between soil and pile surface. In heating mode, thermal effect was opposite to that in cooling mode. In addition, the temperature in concrete pile and soil increased with system running, but the upward trend was reduced. After 10 days, the temperature tended to be stable.

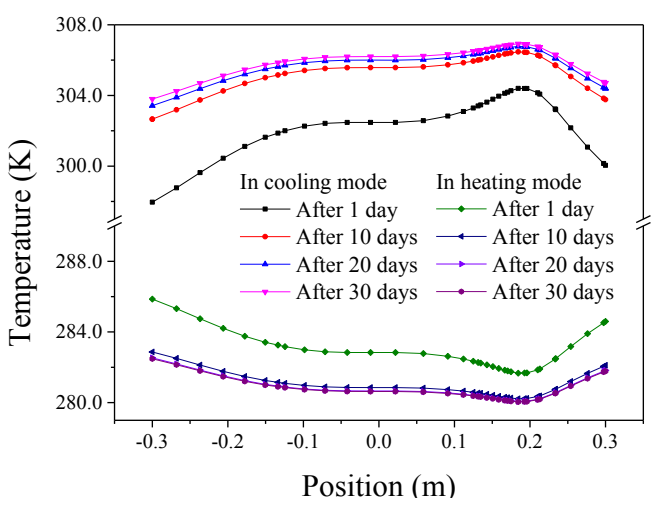

Fig. 3. Temperature distributions on line $\mathrm{L}$ in concrete pile

Heat transfer flux per meter of pile-foundation heat exchanger $(Q)$ is depicted in Fig. 4. It is apparent that maximum value of heat transfer rate was about $270 \mathrm{~W} \cdot \mathrm{m}^{-}$ ${ }^{1}$ and $230 \mathrm{~W} \cdot \mathrm{m}^{-1}$ at the first day in cooling and heating mode. However, the value and attenuation rate was decreasing with system running. After 70 hours, it dropped to $107 \mathrm{~W} \cdot \mathrm{m}^{-1}$ and $87 \mathrm{~W} \cdot \mathrm{m}^{-1}$.

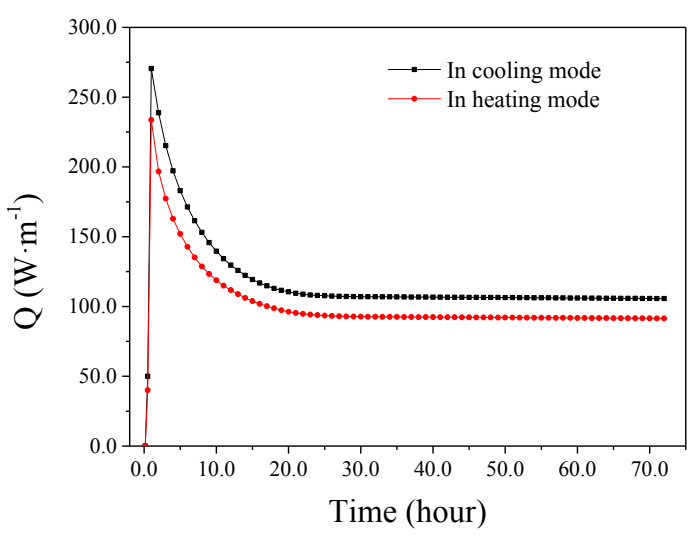

Fig. 4. Heat flux per meter of pile-foundation heat exchanger

\subsection{Pile-foundation heat exchanger group}

To carry out the simulation of heat transfer process for $3 \times 3$ energy piles, an office building located in Nanjing was introduced. The all-year dynamic building load was calculated with DeST, including the cooling period from June to September, the heating period from December to March and two recovery periods, as shown in Fig. 5.

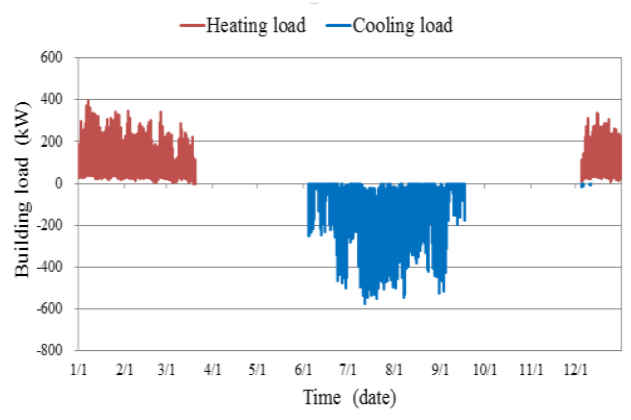

Fig. 5. Building load

The distributions of average soil temperature with system running in non-equilibrium and equilibrium conditions were shown in Fig. 6. In non-equilibrium condition, heat injection into soil in cooling mode was obviously higher than heat extraction from soil in heating mode. After system running for one year, the value of average soil temperature increased by $0.42 \mathrm{~K}$ inevitably. After ten cycles, the value rose to $2.96 \mathrm{~K}$. Furthermore, it would increase ceaselessly with system running. Contrastively, after one year's running in equilibrium condition, the average soil temperature was reduced by $0.16 \mathrm{~K}$, and after ten cycles, the value decreased to $0.61 \mathrm{~K}$. With system running, the average soil temperature tended to be stable at the end of the following cycles. Obviously, the equilibrium condition of cooling and heating load is 
beneficial to the system running safely and efficiently.

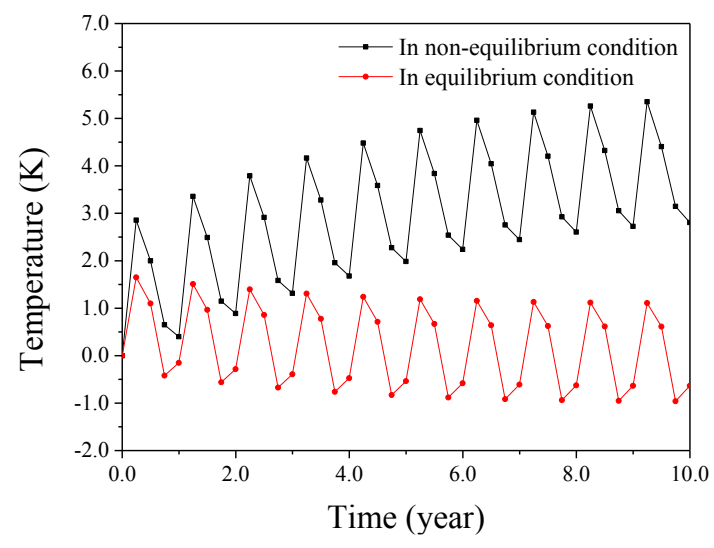

Fig. 6. The distributions of average soil temperature.

\section{CONCLUSION}

In this paper, the treble U-shaped form of geothermal pile-foundation heat exchanger in GSHP system was selected and studied via numerical method. Heat transfer processes of the pile-foundation heat exchanger and heat exchanger group were studied in different condition. It was found that the higher thermal conductivity of pilefoundation heat exchanger contributed to the higher heat transfer efficiency than soil. In cooling mode, the temperature in concrete pile was obviously higher than that in soil. In heating mode, the trend was opposite. After ten year's running, the average soil temperature increased by $2.96 \mathrm{~K}$ in non-equilibrium condition and decreased by $0.61 \mathrm{~K}$ in equilibrium condition. The equilibrium condition of cooling and heating load was beneficial to the system running safely and efficiently. The study results in this paper can be used as theoretical basis for the design and application of pile-foundation heat exchanger in GSHP system.

\section{ACKNOWLEDGEMENTS}

This study is financially supported by National Natural Science Foundation of China (No. 51578146).

\section{REFERENCES}

[1] Eisentraut, A., Brown, A. (2014), Heating without global warming: market development and policy consideration for renewable heat, Organization for Economic Cooperation and Development.

[2] Ting, L., Tianwei, Q. (2012), Analysis on performance and application of ground source heat pump system, Science and Technology Informance (30) : pp. 147-148.

[3] Hehrad, B., Soheil, P., Abbasali, A. (2015), 3-D simulation of heat transfer rate in geothermal pilefoundation heat exchangers with spiral pipe configuration, Applied Thermal Engineering (87) : pp. 655-668.

[4] Florides, G., Christodoulides, P., Pouloupatis, P. (2013), Single and double U-tube ground heat exchangers in multiple-layer substrates Applied Energy (102) : pp. 364-376.

[5] Xin, L. (2016), Heat transfer research and engineering application of energy piles, Shandong Jianzhu University.

[6] Benamar, B., Rachid, S., Hamidou, B., Hakan, O. (2013), Analysis of thermal and dynamic comportment of a geothermal vertical U-tube heat exchanger, Energy and Buildings (58) : pp.37-43.

[7] Chunfeng, Z., Peng, L., Zhiyong, L. (2013), Numerical investigation of heat transfer performance of energy pile in GSHP, Power Generation and Air Condition $(150,34)$ : pp. 40-44.

[8] Zuiliang, M., Yue, L. (2014), Design and application of ground source heat pump system, Machinery Industry Press. 